\title{
O EQUILÍBRIO DO PODER NA REGULAÇÃO DA INTERNET: CRITÉRIOS E CONSEQÜÊNCIAS
}

\author{
Seiiti Arata Jr.' \\ Aluno do Curso de Graduação da Faculdade \\ de Direito da Universidade de São Paulo
}

\begin{abstract}
Resumo:
Nos últimos anos, o advento de formas digitais de comunicação trouxe uma mudança em nossas vidas, repercutindo em diversas áreas da atuação humana como o aprendizado, trabalho, lazer, comércio e mesmo a cidadania. Nosso estudo mostrará que esta evolução do nível de comunicação tem relação com outras mudanças que já aconteciam em outros campos, como a própria vida e a manipulação da matéria, caracterizando um processo sistêmico de alta interação. Essas mudanças são refletidas nas relações de poder dentro da coletividade. Os indivíduos ganham poderes não previstos pelos legisladores. A problemática está localizada no uso destes poderes e o papel que o Estado deve exercer sobre ele. Analisaremos casos da experiência americana, nos quais diferentes abordagens foram tomadas, com diferentes resultados. A regulação obtida é dada através da colaboração entre as forças de mercado, científica e governamental, e não apenas desta última isoladamente. Os problemas apontados não intentam apoiar a corrente libertária, anárquica, de grande força na comunidade online. Ao contrário. É necessário encontrar a técnica ideal para a nova organização de poderes, identificar quais fatores estão envolvidos para que o governo possa corresponder às expectativas de um Estado democrático. Para isso, estudaremos as formas de poder e como o ciberespaço é por elas influenciado. Sendo o objetivo deste estudo discutir as mudanças nas leis brasileiras, faz-se necessário verificar o papel do direito no processo de regulação e saber quando e como aplicá-lo no novo contexto.
\end{abstract}

Abstract:

In the last years, the arrival of digital forms of communication has brought a transformation in our lives, reflecting in different areas of human interaction,

1. Estc artigo ć uma adaptação da monografia "O Processo de Regulação do Comćrcio Elctrônico na Internct: Critćrios c Conseqüĉncias", claborada para a Fapesp $\mathrm{cm}$ caráter de iniciação científica, sob orientação do professor titular Luiz Olavo Baptista, aos quais o autor ć imensamente grato. 
such as learning, working, leisure, trade and even citizenship experiences. Our research will demonstrate that such evolution in the communication experience has a strong relation to other changes already in course in fields such as live itself and the manipulation of matter, characterizing a systemic process of high interaction. Such modifications are reflected in power relations inside the society. Individuals acquire new powers, unforeseen by the legislators. The problem is located in the due use of these powers and the role government should play over it. North American cases, where different approaches were taken, will be analyzed, as well as their results. The regulation obtained is a result not only from the market forces, but also from scientific and governmental ones. The problems identified do not intend to support the libertarian doctrine, which has a strong popularity in online communities. By the contrary. It is necessary to find the ideal technique to the new organization of power structures, identify which forces are involved so that government is able to correspond to the expectations of a democratic state. To do so, the existing forms of power and how cyberspace is influenced by them will be analyzed. Since the purpose of this article is to discuss how modifications in Brazilian laws should be directed, it is necessary to verify the role of Law in the regulation process and to know when and how to be applied in the new context.

Unitermos: Teoria Tridimensional do Direito; propriedade intelectual; Internet; poder; ciberespaço.

\section{I - Descrição do fenômeno}

1. Do molar ao molecular

Uma nova cultura surge com a revolução digital, modificando nossa condição como seres individuais e sociais. Estudando os efeitos da expansão do ciberespaço sobre a cultura humana, o filósofo Pierre Lévy faz uma análise das grandes evoluções tecnológicas, identificando uma tendência ao aumento de precisão da técnica e da interdisciplinaridade. $O$ desenvolvimento das tecnologias moleculares aborda de forma mais precisa os objetos e processos controlados, superando as tecnologias molares, de tratamento em massa de maneira desordenada. As técnicas moleculares reduzem os desperdícios e as rejeições ao mínimo, em alta velocidade, considerando as microestruturas de seus objetos.

O progresso destas tecnologias ocorre em diferente velocidade nos diversos setores da cultura humana. De forma geral, o governo acompanha esta evolução 
em ritmo mais vagaroso, carecendo de uma adaptação aos desafios propostos pela revolıção digital. É necessário superar o descompasso entre as técnicas molares que o soberano deseja aplicar a uma sociedade organizada de forma molecular.

O professor da Universidade de Paris ilustra a aplicação do conceito de tecnologias molares e moleculares em campos como a vida, a matéria e a informação:

Na vida, anterior à molar e à molecular, a técnica arcaica transformava as espécies sem incidência de qualquer elemento de vontade humana. Com a agricultura e a pecuária, os homens iniciam uma seleção artificial, técnica molar de escolha de certas plantas é animais. Esta técnica, apesar de ser muito mais rápida que a arcaica, apresenta baixa eficácia quando comparada à técnica molecular: a influência direta nos genes, nas moléculas.

As técnicas de domínio da matéria são classificadas em três categorias: mecânicas, quentes e frias. As mecânicas estão ligadas aos primórdios da existência humana, produzindo ferramentas como lanças e machados. Transformando as qualidades dos materiais e gerando energia, as técnicas quentes despontam com a Revolução Industrial através das técnicas de uso do carvão e do vapor; sua eficácia é muito maior, apesar de ainda serem classificadas como molares. As técnicas frias ou moleculares seriam a nanotecnologia, o uso de supercondutores, a manipulação atômica e subatômica da matéria.

No campo da informação, as técnicas de controle de mensagens podem ser somáticas, midiáticas e digitais. As somáticas implicam a presença efetiva para a produção de signos, como as performances ao vivo de espetáculos. As midiáticas fixam essas mensagens, podendo reproduzi-las de forma independente no espaço e no tempo, através dos sistemas de reprodução de textos, imagens e sons, como a imprensa, a fotografia, a televisão. As midias transportam as mensagens em escala que os meios somáticos jamais poderiam conseguir. Entretanto, neste processo, descontextualizam tais mensagens. São técnicas molares, agindo sobre as mensagens a partir de fora, por alto e em massa; é çlara a distinção entre transmissor e receptor. Finalmente, a informática, garantindo um controle total da microestrutura das mensagens, manipulando os bits, é uma técnica molecular, pois não apenas as transmite, mas permite que elas sejam modificadas; assim é o hipertexto, diferente do texto tradicional, estático. "O tratamento molecular da informação" segundo Lévy, "abre um ciberespaço que interconecta virtualmente todas as mensagens digitais, multiplica os captadores e 'semáforos', generaliza as interações e os cálculos em tempo real'. O hipertexto recupera a contextualização perdida pelas técnicas molares. 
Mais do que meros exemplos isolados, as evoluções apresentadas por Lévy interagem entre si, condicionando-se mutuamente na forma de uma espiral ascendente. Sem os avanços da informática, por exemplo, as técnicas de engenharia genética e nanotecnologia não poderiam ter sido desenvolvidas; o avanço das técnicas de manipulação de materiais influenciam o avanço digital, com a fabricação de microchips e redes de fibra ótica.

As repercussões não se restringem a campos eminentemente técnicos, mas influenciam também a dimensão humana de forma impressionante. O sociólogo Manuel Castells, destacando os principais aspectos do paradigma da tecnologia da informação, faz referência à penetrabilidade dos efeitos das novas tecnologias: sendo todas as atividades humanas dependentes de informação, os novos meios tecnológicos de transmissão de informações influenciam os processos de nossa existência individual e coletiva.

Ilustra esta afirmação a discrição que os indivíduos começavam a formar sobre a informação recebida e suas crenças, conforme impressos eram disponibilizados pela imprensa de Gutemberg. Em 1542, Johann Sleidan, historiador alemão, fazia referência à arte da imprensa e seus efeitos: "Each man became eager for knowledge, not without feeling a sense of amazement at his former blindness" "Um exemplo fresco em nossas memórias é a força que a nova tecnologia de transmissão de informações exerceu no processo de revolução na Europa Oriental no fim deste século.

No processo de evolução para as técnicas moleculares, a coletividade humana é, assim, influenciada por vários impulsos. Para que o Direito possa vislumbrar as possibịilidades e exigências da inteligência coletiva, cumprindo seu papel de manutenção da ordem social neste processo, não devemos aplicar cegamente as regras existentes. Tampouco é necessário reinventar a roda: devemos entender os princípios basilares das normas já testadas e aprovadas pelo tempo e adequá-los ao novo contexto.

\section{A coletividade molecular}

As técnicas moleculares da informática têm como resultado direto um aumento do poder individual de controlar o fluxo de informações, além de uma série de efeitos indiretos.

2. Michacl Hauben, The Expanding Comnonwealth of Learning: Printing and the Net Capturado $\mathrm{cm}$ 17 sct. 2000. Onlinc. http://wuarchive.wustl.cdu/doc/misc/acn/nctbook/ch.9_printing 
Nos primeiros anos subseqüentes ao lançamento comercial dos computadores pessoais, a opinião geral dos consumidores era de que computadores eram máquinas enormes, bizarras e distantes da realidade cotidiana. Os comandos, a comunicação entre a máquina e o usuário, eram feitos através de fórmulas arcanas conhecidas por poucos. Reconhecendo este problema, os fabricantes de produtos informáticos iniciaram as pesquisas para o desenvolvimento de computadores que proporcionassem um maior conforto para o usuário, aumentando o seu poder de controle sobre a máquina, facilitando a comunicação. Para isso, fugindo do padrão textual dos Personal Computers (PCs) disponíveis, a Apple lançou o Macintosh, o primeiro PC com interface gráfica e um mouse. O conceito icônico "user-friendly" de pastas, menus e lixeiras foi mais tarde seguido pela Microsoft com o ambiente Windows, consagrando um mercado de massa onde os usuários ganharam de forma geral um poder maior sobre seus computadores.

Até a explosão da Internet, este controle estava restrito à produção e gerenciamento dos arquivos pessoais, à mudança na cor da tela, ao tamanho das letras, à aparência do desktop. Com a técnica de tratamento da informação em nível molecular, este universo é expandido: é possivel a interação com diferentes comunidades online, rastreamento de documentos, personalização de notícias, comprar, estudar e trabalhar à distância. A tecnologia evolui de forma a tornar cada vez mais sutil a distinção entre o espaço material e o ciberespaço.

As ações online dos indivíduos têm certamente um impacto na vida de outros indivíduos e da comunidade. A facilidade de reprodução de dados que os indivíduos encontram no meio digital, prejudicando os titulares de direitos autorais, por exemplo, trouxe inúmeros debates sobre a propriedade intelectual, conflito que será tratado no capítulo dois.

Estamos diante de uma mudança nas relações de poder devido ao progresso da tecnologia. O nível de poder é uma medida usada para avaliar diferenças entre indivíduos quanto a certas capacidades de atuação. Um de seus componentes é o nível de tecnologia e o grau de influência que esta exerce sobre as relações humanas. Nas relações online, a interação entre homem e máquina é muito forte, inspirando a literatura de ficção a explorar os limites entre esta relação entre corpo, alma, máquina e conhecimento ${ }^{3}$, aceitando ou não a nossa condição

3. A cssc respeito, a obra de William Gibson, Neuromancer, é freqüentemente lembrada como a primcira cxploração do conccito de cibcrespaço como um mundo de informações, onde humanos podiam scparar-sc de scus corpos, receptáculos que os prendiam ao mundo matcrial. 
como ciborgues ${ }^{4}$ na chegada do novo milênio, reconhecemos que a dependência da tecnologia é uma importante influência sobre nossas capacidades de ação.

O poder é uma boa medida para analisar o ciberespaço, onde não é simples identificar as bordas entre o social, o cultural e o tecnológico ${ }^{5}$ O poder direciona a discussão para questionamentos sobre que pode ser feito, quem tem poder e quem não. O poder permite que comecemos com a presunção de que as análises sociológicas, políticas e culturais de sociedades baseadas na tecnologia estão intimamente ligadas.

\section{Foucault e o poder}

Conforme o homem produz e encontra novas necessidades e desenvolve a tecnologia para a sua satisfação, as normas que regulam as potenciais relações tornamse mais numerosas e complexas. Tais normas existem não apenas no plano de governador e governados, mas nas várias esferas de poder como a família, igreja, empresas, organizações internacionais.

Para Michel Foucault, poder é uma força que gera estruturas de desigualdades entre as pessoas; o poder é uma relação e não uma posse. É constituído por um conjunto de táticas que afetam o cotidiano, mas independente de uma força de vontade orientadora, seja individual ou organizacional. A microfísica do poder está difusa por toda a sociedade, sujeitando os indivíduos a uma estrutura de deveres formais e agressões informais.

A visão de poder de Foucault é interessante por desafiar a idéia de poder como soberania tão-somente: além do triângulo "soberano - cidadão - direito", devemos ter uma noção de vigilância e disciplina, de formas mais sutis, privadas, informais e materiais de coerção. Os avanços tecnológicos permitem um inédito armazenamento e manipulação de informações, que podem ser usadas com diversos propósitos.

Foucault aponta para o aparente conflito da coexistência de uma linguagem formal de política organizada pelas relações entre soberano e cidadão, expressa por regras e sanções aplicáveis ex post facto, ao lado de uma verdadeira

4. Nosso cstado como ciborgues, homens-máquina, ć apresentada por Tim Jordan, que instiga scus lcitores dizendo que ć póssivel argumentar que os óculos inauguraram o primciro cstágio para a aparição dos ciborgues. Da mesma forma que as lentes ampliaram a capacidade de visão, as redes informáticas podem auxiliar os homens a atingir um patamar supcrior de comunicação.

5. Tim Jordan, Cyberspace: the Culture and Politics of Cyberspace and the Internet, 1" cd., London, Routledgc, 1999, p.8. 
experiência de poder exercida por várias fontes não-estatais ${ }^{6}$ que freqüentemente dependem de meios materiais ou tecnológicos de execução de suas ordens. Esta multiplicidade de fontes de poder é um dos pontos críticos da regulação do comércio eletrônico, pelo aumento do poder privado alterando o equilíbrio vislumbrado pelos antigos legisladores. É neste âmbito que argumentamos que as antigas normas não estão adequadas para lidar com as novas relações de poder.

O pensamento de Foucault é, nesse sentido, o mais apropriado para analisar as forças de poder no ciberespaço, por considerar diversas forças regulatórias e suas respectivas esferas de influência. James Boyle contrapõe Foucault à visão de um direito positivo, um comando apoiado em ameaças, sanções, emanadas por um soberano, direcionadas a uma população geograficamente definida que deve àquele soberano total obediência. Tal conceito é claramente inadequado para lidar com a vida no ciberespaço.

A análise de poder de Foucault é uma análise das formas de governância, não de governo. Governância é a análise de todos os vetores, não apenas institucionais, que regulam nossa conduta, nossás possibilidades. Não são tão-somente as formas de ação do Estado sobre seu povo mas também as dos indivíduos consigo mesmos.

Nosso estudo buscará identificar as forças regulatórias atuantes no ciberespaço, sua constituição, sua arquitetura, estruturas e limites direcionados a certos valores. Afinal, como toda tecnologia desenvolvida por homens, a Internet possui uma série de valores. Este é o primeiro princípio do Tecnorrealismo ${ }^{7}$ Devemos fugir do mito da neutralidade, de que, por ser um artefato inanimado, a tecnologia é neutra, não estimula certas formas de comportamento. Ao contrário, as tecnologias são repletas de conseqüências, algumas desejadas, outras imprevistas, nos campos político, social, cultural e econômico.

4. Tecnopoder, código

O tecnopoder, para Tim Jordan, é a constante oscilação, mutação entre os objetos que parecem ser neutros, como teclados, monitores, software de comunicação,

6. Conforme James Boylc, Foucault in Cyberspace: Suveillance. Sovereignty, and Hard-Wired Censors. Capturado cm 17 sct. 2000. Onlinc. http://www.tprc.org/abstracts97/foucault.htm

7. O Tecnorrcalismo busca a comprecnsão das implicações sociais c políticas das tecnologias de forma a alcançar um maior controlc sobre a construção do futuro, analisando como as novas tecnologias podem auxiliar ou prejudicar a qualidade de vida pessoal, comunitária c as cstruturas cconômicas, políticas c sociais. Mais informaçõcs cm http://www.tcchnorcalism.org 
e os valores sociais e éticos imbuídos nestes objetos. Um questiona o outro. Se um fórum de discussões online permite que o conteúdo de uma mensagem torne-se mais poderoso do que a eloquiência de seu orador ${ }^{8}$ podemos perguntar o porquê desta mudança, quem foram os arquitetos desta estrutura de comunicação, que fins eles tinham em mente e quais finalidades foram alcançadas.

Além do Governo e do setor empresarial, existem vários grupos com diversos interesses participando da construção da arquitetura do ciberespaço. $O$ trecho abaixo foi transcrito de " $A$ Cypherpunk's Manifesto":?

"We must defend our own privacy if we expect to have any. We must come together and create systems which allow anonymous transactions to take place. People have been defending their own privacy for centuries with whispers, darkness, envelopes, closed doors, secret handshakes, and couriers. The technologies of the past did not allow for strong privacy, but electronic teclnnologies do. We the Cypherpunks are dedicated to building anonymous systems. We are defending our privacy with cryptography, with anonymous mail forwarding systems, with digital signatures, and with electronic money. Cypherpunks write code. We know that someone has to write software to defend privacy, and since we can't get privacy unless we all do, we're going to write it. We publish our code so that our fellow Cypherpunks may practice and play with it. Our code is free for all to use, worldwide. We don't mucl care if you don't approve of the software we write. We know that software can't be destroyed and that a widely dispersed system can't be shut down"

$O$ tecnopoder está presente tanto nos ambientes online como offline, materializando pela tecnologia as mais diversas preferências, como a velocidade e segurança de automóveis ou mesmo o sabor e temperatura de sorvetes ${ }^{\prime \prime}$ Estamos cercados de artefatos tecnológicos que refletem valores sociais. A diferença entre o mundo material e o ciberespaço é que no último as relações sociais dependem fundamentalmente, se não completamente, de tecnopoderes.

8. Em uma hipotética rcunião no mundo matcrial, as pessoas mais carismáticas c cloqüentes tcriam a tendência de atrair maior atençào de sua platćia do que os oradores mais tímidos, de voz baixa. Isso acontecc, entrc outros motivos, pois a nossa capacidade de reconliccimento sonoro permitc que poucas pessoas falcm simultancamentc. Uma discussão online não ć assim limitada $\mathrm{c} \mathrm{cm}$ geral ganham maior atenção (por cxcmplo sob a forma de respostas às mensagens publicadas para comentários) aqueles que fazcm comentários construtivos c polêmicos.

9. Eric Hughes, A Cypherpunk's Manifesto. Capturado cm 17 sct. 2000. Onlinc. http://www.eff.org/ pub/Privacy/Crypto_misc/cyphcrpunk.manifesto

10. Tim Jordan, 1999, p.113. 
Argumentamos que as estruturas do tecnopoder no ciberespaço são mais flexíveis, dinâmicas, já que a Internet pode ser modificada com facilidade e," através do seu Código ${ }^{\prime 2}$ como denomina o constitucionalista americano Lawrence Lessig.

O Código é que determina como a informação flui online e quem pode controlá-la. O Código é a criação dos programadores, como os tais cypherpunks: "Cypherpunks write code". Software, periféricos, protocolos técnicos, designs de rede constituem o ciberespaço tal como o conhecemos. "Código" nesta concepção, pode variar dependendo do contexto. Parte do Código está na camada IP (Internet Protocol), onde os protocolos de intercâmbio de dados, como o TCP/IP, operam. Parte do Código está acima da camada IP, que é a de maior relevância para a teoria de Lessig. Esta camada superior incluiria os aplicativos que podem interagir com a rede, como browsers e programas de e-mail, bem como plataformas de sistemas operacionais sobre as quais tais aplicativos podem funcionar. A natureza do ciberespaço é definida pelo Código que predomina em determinado momento. Entretanto, novos padrões para o Código podem ser desenvolvidos e aceitos, o que influencia no produto final da regulação, como analisaremos em nosso estudo.

Os primeiros pensamentos sobre o ciberespaço partiam da premissa de que o governo não poderia regular o ciberespaço e que desta forma este permaneceria inevitável e essencialmente livre. Contrariamente às manifestações de pensamento desta primeira geração de pensadores, como a famosa Declaração de Independência do Ciberespaço ${ }^{\prime 3}$ de John Perry Barlow, afirmamos que o Código não é estático; logo, não nos garante liberdade ou justiça, muito menos o desaparecimento do Estado.

A regulabilidade das ações no ciberespaço depende de sua arquitetura. É exatamente sobre o controle do Código que repousam os conflitos sobre o futuro. Com algumas arquiteturas, o comportamento no ciberespaço pode ser facilmente controlado. Com outras, não.

Lessig, em "Code and other laws of cyberspace", lidera a corrente de pensamento de que o desenvolvimento da arquitetura está caminhando no sentido de

II. Dentro do modelo chamado Open Systems Intcrconnect, as modificações a que nos referimos scriam aquelas dirccionadas à camada dc aplicação.

12. Ou Lex Informatica, como prefere Jocl Reidenberg $\mathrm{cm}$ littp://www.privacy.fgov.be/conference/ pt4_2.html

13. A Declaração de Independência do Ciberespaço pode ser cncontrada $\mathrm{cm}$ http://www.cft.org/ -barlow/Dcclaration-Final.html 
uma maior regulação. A anterior "natureza" de desregulação está sendo modificada pelo setor privado, amparado pelo governo, para permitir o desenvolvimento do comércio eletrônico.

\section{Código. Forças regulatórias.}

Para a New Chicago School, de Lessig, sobre a coletividade influem quatro fatores regulatórios com suas respectivas repreensões: (i) leis e sanções; (ii) normas sociais e estigmas impostos pela comunidade; (iii) mercado e preço e (iv) arquitetura e suas restrições físicas, sendo a regulação final um produto destes vetores. Para elucidar o conceito, ele usa a regulação sobre o fumo como exemplo, apontando os fatores que influenciam diretamente na decisão de acender um cigarro:

Pela dimensão legal, o fumo é restrito em certas condições, como no interior de aviões e elevadores. Menores de idade também não podem adquirir cigarros. As normas de convívio social dizem que o fumo não é recomendado dentro de um carro junto com não-fumantes, ou durante uma refeição. O mercado por sua vez influencia pelo preço e variedade de cigarros disponíveis. Finalmente, os limites da tecnologia, da arquitetura dos cigarros, encontram-se na quantidade de nicotina e nos seus efeitos de dependência química. Dos elementos apresentados, alguns têm maior influência que os outros, porém uma análise completa considera todos eles, para um balanço efetivo. Este mesmo modelo pode ser usado para a análise do ciberespaço.

A descrição é simplista, apresentando a regulação como resultado de influência direta das forças sobre o comportamento. Mais adiante veremos como as dimensões interagem entre si, regulando o comportamento de forma indireta.

No ciberespaço, as dimensões da New Chicago School atuam de forma semelhante. A lei regula o comportamento através da imposição de sanções pela violação de suas previsões. As normas também regulam pelas sanções impostas diretamente por uma comunidade online ${ }^{14}$ ou indiretamente pela comunidade offline que associa as ações cometidas no ciberespaço aos indivíduos no espaço material. Os mercados regulam através do preço, atraindo e afastando consumidores e anunciantes. A arquitetura do ciberespaço é o Código, criando o ciberespaço e as regras que dão liberdades e restrições ao comportamento conforme as especificações e valores escolhidos pelos programadores do Código.

14. O modclo de negócios do web site de "Icilão" cBay, por cxemplo, procura criar uma comunidade onde os compradores c vendedores recebem "notas", cstabclecendo sua reputação c aumentando sua credibilidadc. 
Essa análise do Direito como um sistema dinâmico e multidimensional aproxima-se da célebre Teoria Tridimensional do Direito. Para Miguel Reale, "a norma jurídica é a indicação de um caminho, porém, para percorrer um caminho, eu devo partir de determinado ponto e ser guiado por certa direção: o ponto de partida da norma é o fato, rumo a determinado valor"'s

A força que o mercado exerce para a regulação, mencionada na teoria de Lessig, não será levada em consideração como uma dimensão independente, visto que pode ser incorporada pelas outras dimensões.

Segundo Miguel Reale,

“a) onde quer que haja um fenômeno jurídico, há, sempre e necessariamente, um fato subjacente (fato econômico, geográfico, demográfico, de ordem técnica, etc.); um valor, que confere determinada significação a esse fato, inclinando ou determinando a ação dos homens no sentido de atingir ou preservar certa finalidade ou objetivo; e, finalmente, uma regra ou norma, que representa a relação ou medida que integra um daqueles elementos ao outro, o fato ao valor;

b) tais elementos ou fatores (fato, valor e norma) não existem separados uns dos outros, mas coexistem numa realidade concreta;

c) mais ainda, esses elementos ou fatores não-só se exigem reciprocamente, mas atuam como elos de um processo (já vimos que o Direito é uma realidade histórico-cultural) de tal modo que a vida do Direito resulta da integração dinâmica e dialética dos três elementos que a integram."”o

O progresso tecnológico, mudança no plano fático, implica em modificações na forma como a lei é aplicada. As dimensões do Direito não são totalmente independentes; elas interagem. Para melhor compreender a Teoria, o professor Reale, em aula proferida na Universidade do Rio de Janeiro, ofertou a seus alunos o seguinte caso:

"Eu tive um fato muito curioso. Havia em São Paulo, uma grande casa de modas, chamada Casa Vogue, que era, digamos assim, o esplendor da moda feminina. A Casa Vogue cresceu muito, cresceu tanto que o dono da casa, que era meu cliente, resolveu derrubar uma parede para aumentar a sua oficina. Sabendo disso, o locador entrou na mesma hora com uma ação de despejo, porque havia uma cláusula no contrato

15. Migucl Reale, Linha evolutiva da teoria tridimensional do Direito, Revista da Faculdade de Dircito, São Paulo, v. 88, p. 303, 1993.

16. Migucl Reale, Lições preliminares de Direito. 1 cd. São Paulo : José Bushatsky, p.74, 1974. 
que proibia alterações no imóvel locado. Aceitando a causa, procurei no Código Civil um artigo, segundo o qual os tapumes, as paredes divisórias de madeira, podem ser removidos livremente pelo locatário. Então eu disse ao Tribunal de São Paulo mais ou menos o seguinte: 'Ilustres desembargadores, o que houve foi uma mudança essencial no plano dos fatos. O Código Civil brasileiro foi feito numa época em que as paredes sustentavam edificios, mas, hoje em dia, quando os edificios têm estrutura metálica, ou de cimento armado, as paredes internas são removíveis como se fossem tapumes, não afetam a estrutura do edifício. Quando o inquilino sair, no término do contrato, ele reporá a parede no lugar' Eu ganhei a causa e ganhei mais experiência jurídica"' 17

Foram descritas as dimensões que regulam o indivíduo. Tais dimensões podem ser modificadas. No caso analisado, a lei foi alterada mediante o fato, ou arquitetura: a evolução das técnicas de construção implicou em mudanças na cláusula contratual por uma ampliação da interpretação da lei.

Para nosso estudo, são importantes as mudanças que a lei e a arquitetura terão influenciando as outras dimensões, por ser a lei a dimensão mais auto-consciente e a arquitetura a mais penetrante.

A lei funciona em duas formas distintas: de forma direta, indicando como os indivíduos devem se comportar e os ameaçando com sanções caso descumpram as regras, e de forma indireta, buscando modificar as outras forças regulatórias. A influência da lei sobre as outras forças é uma regulação indireta. Retomando o exemplo do combate ao fumo: ${ }^{18}$ o Governo pode usar a lei diretamente, proibindo o fumo em locais públicos, ${ }^{19}$ desta forma regulando diretamente o comportamento que deseja modificar. Ou a lei poderia influenciar indiretamente, criando uma campanha de âmbito nacional, visando alertar a população sobre os malefícios advindos com o hábito do fumo, ${ }^{20}$ assim, modificando as normas sociais como maneira de controlar o comportamento. Ou então a lei poderia agir de forma indireta exigindo que os fabricantes reduzam o

17. Migucl Reale, 1993, p.310.

18. Excmplo dado por Lawrence Lessig cm Code and Other Laws of Cyberspace. Ist. ed. Cambridge: Harvard Press, 1999.

19. Ver, por cxcmplo, a Lci Estadual n" 11.999, de 3 de agosto de 1992, do Estado do Ccará, quc dispõc sobre a proibição do uso do fumo $\mathrm{cm}$ cstabclecimcntos da rede cstadual de Saúde c de Educação bcm como nos vcículos de transportes colctivos intcrmunicipais.

20. É o tcxto do artigo I" da Lci n.7.488, de 11 de junho de 1986, que institui o Dia Nacional dc Combatc ao Fumo. 
nível de nicotina, desta forma regulando o plano dos fatos de modo que a dependência química pelos cigarros diminuísse e, assim, diminuindo seu consumo.

Cada uma destas ações teria uma certa vantagem e um certo custo. A verdadeira arte é saber balancear estas formas de regulação, de modo a obter um resultado otimizado. E, para o ciberespaço, considerada a teoria do tecnopoder, uma maneira interessante de obter a regulação é através dos fatos: modificando a própria arquitetura ou das instituições que produzem a arquitetura, como tentou o $\mathrm{FBI},{ }^{21}$ solicitando que a Internet Engineering Task Force, um dos organismos que participa do processo de padronização do ciberespaço, ${ }^{22}$ produzisse um novo modelo para que permitisse a interceptação das comunicações na Internet, de maneira semelhante como foi feito com a modificação dos padrões dá arquitetura de telefonia digital, para facilitar a quebra do sigilo telefônico. ${ }^{23}$

Vemos que as formas indiretas de regulação são mais sutis e assim devemos sempre estar atentos aos valores fundamentais da sociedade a que se destina proteger. O problema não é com a regulação indireta, mas sim sobre a transparência deste processo. Em uma democracia as regulações devem ser públicas.

A idéia do tecnopoder expande as ferramentas que o Governo pode usar para a regulação, dada a dependência que o ciberespaço tem da tecnologia. O Código torna-se mais uma ferramenta de regulação. Indiretamente, regulando a produção do Código, o Governo pode atingir fins regulatórios. Devemos estar atentos a esta regulação pois ainda não temos uma noção clara sobre os valores relacionados a esta crescente eficiência regulatória. Lembrando a fórmula realeana de que "o Direito é uma integração normativa de fatos segundo valores," é imprescindivel estabelecer quais são os valores que devem orientar a produção legislativa.

Tal possibilidade já havia sido apresentada pela visão pioneira de Luiz Olavo Baptista, em tese de 1986:

“Já no que se refere aos controles prévios não se pode dizer o mesmo. $O$ fato de que as TEIF podem ser originadas quer de um cartão de crédito, quer de um

21. McCUllaGH, Declan. IETF Says 'No Way' to Net Taps. Wircd News, Washington, II nov. 1999. http://www.wircd.com/ncws/politics/0,1283,32455,00.html

22. INTERNET ENGINEERING TASK FORCE. Overvicw of the IETF. Capturado $\mathrm{cm} 17 \mathrm{sct} .2000$. Onlinc. http://www.ietf.org/overvicw.html

23. Communications Assistance of Law Enforcement Act (CALEA), Pub. L. No. 103-414, 108 Stat. 4279 (codificd at 47 U.S.C. $\$ \S 1001-1010$ ), solicitando que companhias tclefônicas sclecionasscm uma arquitctura de rede que facilitassem a cscuta telcfônica. 
terminal situado em um estabelecimento comercial ou industrial qualquer, ou mesmo em terminais abertos ao público dia e noite, apresenta problemas que deverão ser resolvidos não só em termos regulamentares, mas, também, em termos de programação. Aqui, colocase um interessante problema para os estudiosos de Teoria Geral do Direito, o da possibilidade de existência de regras de conduta, dirigidas às pessoas, via computador!"

Este controle da conduta via computador deve estar orientado de acordo com os princípios já existentes. Para o professor da Faculdade de Direito da Universidade Harvard, Laurence Tribe, devemos encontrar maneiras de neutralizar a tecnologia, mantendo os valores originais da Constituição, papel que deve ser exercido pelos juízes:

"Constitutional principles should not 'vary with accidents of technology' In a sense, that's the fifth and final constitutional axiom I would urge upon this gathering: that the Constitution's norms, at their deepest level, must be invariant under merely 'technological' transformations. Our constitutional law evolves through judicial interpretation, case by case, in a process of reasoning by analogy from precedent. At its best, that process is ideally suited to seeing beneath the surface and extracting. deeper principles from prior decisions. At its worst, though, the same process can get bogged down in superficial aspects of preexisting examples, fixating upon unessential features while overlooking underlying principles and values"24

Concordamos que o método mais adequado é ler a Constituição de forma diferente, para proteger na mesma medida os valores que ela prevê. Entretanto, em alguns casos esta releitura não será simples, e poderemos nos deparar com o que Lessig chama de ambigüidades latentes, momentos em que deveremos fazer uma escolha entre diferentes possíveis alternativas, cada uma coerente com os valores constitucionais. São pontos não tratados com clareza pelos legisladores, novos tópicos. Esta novidade pode transpirar um caráter político nas decisões a serem tomadas e as Cortes podem preferir deixar tais discussões para os legisladores, como o juiz Kaplan fez no julgamento do caso DeCSS que será analisado.

A revolução digital abala novamente a presunção da existência de um ordenamento jurídico completo. Devemos nos preparar para preencher novas lacunas. Apesar da releitura ser uma das formas para lidar com estes novos desafios, a simples análise das decisões e valores do passado pode revelar não ser suficiente, como no caso das ambigüidades latentes.

A releitura em particular é uma técnica útil para a decisão de conflitos

24. Laurence Tribc, The Constitution in Cyberspace. Capturado $\mathrm{cm} 17$ set. 2000. Onlinc. http:// www.sjgames.com/SS/tribc.html 
dentro de uma ordem interna, por fazer referência aos valores constitucionais de um povo. Entretanto, muitos são os problemas que estão interconectados no espaço mundializado, em um nível superior e mais amplo. Os sistemas de governos não estão preparados para responder a estas exigências.

Lessig reconhece que a releitura tem suas limitações. Destacamos os casos, nos quais a base tecnológica comum do ciberespaço gera uma nova dimensão de demandas que não tem seus efeitos limitados a uma cultura e sistema jurídico regional, mas de influência global. Deve então o direito internacional ocupar-se de organizar as jurisdições nacionais e uniformizar uma norma para atender com eqüidade a todos. ${ }^{25}$ O Direito Internacional leva em conta o poder das situações transnacionais, que podem envolver indivíduos, empresas, Estados, organizações de Estado, ou outros grupos.

\section{Duas questões de propriedade intelectual}

Na primeira parte mostramos como a revolução digital altera o anterior equilíbrio de poder e que indivíduos, organizações e governos reagem de formas distintas a essas mudanças. Neste processo, o papel do Estado é questionado pelo aumento de poder de seus nacionais e pelas dificuldades que a Internet apresenta à regulação tal como sua arquitetura é encontrada hoje.

Nesta parte vamos analisar a aplicação dos conceitos já desenvolvidos a duas questões relacionadas ao campo da propriedade intelectual: sistemas de proteção a direitos autorais e patentes de software. A tecnologia, como ferramenta de controle, pode atuar de forma a assegurar a manutenção de certos valores.

Todavia, existe a possibilidade de um exagero no uso deste controle, um fenômeno que Andrew Shapiro chama de overșteer, "derrapagem". A analogia simboliza o motorista inexperiente que tenta exercer, em uma manobra, uma força tão grande que acaba perdendo o controle, indo além do planejado, com conseqüências perigosas. Conforme abraçamos o potencial de controle que o ciberespaço nos oferece, devemos lidar com este poder com cuidado.

Analisamos aqui as consequiências dos critérios para a adaptação jurídica às novas relações humanas. A análise apenas de Jurisprudência nacional ficaria prejudicada em razão da escassez de casos relacionados ao tema no Brasil. Desta forma nossa pesquisa recebeu uma abordagem com enfoque na experiência dos Estados

25. Esta tendência ć visivel na Política Uniforme de Resolução de Disputas sobre nomes de dominio claborada pcla ICANN sncontrada $\mathrm{cm}$ http://www.icann.org/udrp/udrp.htm 
Unidos, devido ao seu relativo avanço jurisprudencial, doutrinário e legislativo sobre a matéria. Entretanto, em especial no que se refere ao Direito de Autor, o estudo de Direito Comparado exige cuidado com as distinções entre os sistemas jurídicos analisados, em especial o sistema individual e o comercial.

O sistema individual, Droit d'Auteur, é o da Convenção de Berna, subjetivo, buscando a proteção do autor. Caracterizam este regime o alcance limitado das convenções celebradas pelo autor para a exploração da obra, a interpretação estrita dessas convenções, criando limites contratuais em defesa dos interesses do criador e a proteção independentemente de registro.

O sistema comercial, copyright, é o desenvolvido nos países de influência anglo-saxã. É objetivo, voltado para a obra em si. O copyright é concedido ao titular, sendo exigidas algumas formalidades para seu exercício de exclusividade conforme definido pela Convenção de Genebra, de 1952.

Independentemente do sistema de proteção autoral, fato é que a perfeição das cópias feitas, através de sistemas digitais e o relativo baixo custo associado a estas cópias levou a uma crença de que o sistema de direitos autorais era inefíciente para proteger as criações intelectuais na Internet. John Perry Barlow chegou a afirmar que tudo o que sabíamos sobre a propriedade intelectual até então estava errado. ${ }^{26}$ Além desses argumentos, predominava o sentimento de que o governo não teria como rastrear e punir aqueles que violassem os direitos.

Estas discussões causaram pânico para a indústria privada e para os operadores do Direito, que, para equilibrar a mudança causada pela tecnologia, pretendia ampliar os direitos de propriedade intelectual.

A batalha entre a tecnologia e a norma jurídica faz parte da história do Direito Autoral. Antes do advento da imprensa, os custos associados à cópia das obras artísticas eram tão grandes que não justificavam a existência de uma proteção por parte do Governo, através de leis. Analisando o progresso da propriedade intelectual, percebemos um delicado equilíbrio entre a ampliação dos direitos concedidos pelo Estado e as ameaças da tecnologia em facilitar a cópia.

\section{Copyright management systems}

A novidade trazida pela revolução digital é o uso da própria tecnologia para proteger a propriedade intelectual. Cada vez mais os sistemas de criptografia e

26. John P. Barlow, Selling wine without bottles. Capturado $\mathrm{cm} I 7$ sct. 2000. Onlinc. http://www.cff.org/ pub/Publications/John_Perry_Barlow/HTML/idea_cconomy_articlc.html 
segurança tendem a proteger os autores. Estas ferramentas são conhecidas de forma genérica como Copyright Management Systems (CMS), com premissas nos trusted systems ou secure digital envelopes que protegem o conteúdo autoral dando acesso e subsequente cópia ou impressão apenas na extensão das concessões do autor original. ${ }^{27}$ Mark Stefik assim descreve o trusted system:

"A trusted system is a system that can be relied on to follow certain rules. In the context of digital works, a trusted system follows rules governing the terms, conditions and fees for using digital works. Suppose that you have a digital work stored on a trusted system, and you do not have a right to copy the work. Then if you ask the trusted system to make a copy, it simply will not do it. Instead, it will give you an error message. If you do have a right to copy and, for example, exercising the right requires paying a fee and certification that you are over 18 years old, then the trusted system would first make sure that the conditions are satisfied. Only then would it make the copy.

Suppose that a customer then wants to buy the digital work. In a typical case, he would use a network browser to select the digital work from an on-line distributor. At this point, the two systems-the consumer's system and the distributor's system-need to establish that they are both trusted systems and to determine their security levels and billing methods. One way to do this is with a challenge-response protocol. This protocol is similar to what you might imagine in a spy versus spy. scenario when two secret agents who are strangers to one another first meet."28

Diferentemente de leis ou contratos, que necessitam da participação do Judiciário para executar suas previsões, através de sanções após a ocorrência das infrações, a proteção através da tecnologia cria barreiras à própria violação. Este sistema de proteção torna-se mais poderoso ainda quando amparado pela lei, pela regulação indireta.

A regulação indireta a que nos referimos é a da lei regulando a tecnologia. O desenvolvimento de técnicas de fraude a sistemas de proteção sempre caracterizou uma verdadeira corrida entre as formas de segurança e as técnicas de fraude. Entretanto, a lei pode contribuir com a regulação indireta, como fez a Digital Millennium Copyright

27. Conforme Charles Clark, The Publisher in the Digital World http://associnst.ox.ac.uk/ icsuinfo/ clark.htm c Mark Stefik, Shifting the Possible: How Digital Property Rights Challenge Us to Rethink Digital Publishing http://www.law.bcrkeley.cdu/journals/btlj/articles/12_1/Stefik/html/text.html

28. Mark Stcfik, Shifting the possible 
Act (DMCA) norte-americana, que incluiu a previsão de antifraude, que considera crime praticamente toda tentativa de fraude aos sistemas de proteção de direitos autorais, assim como a produção e oferecimento ao público deste tipo de tecnologia.

O DMCA foi promulgado em outubro de 1998 como uma adaptação à lei de copyright para a era digital, resultado do WIPO Copyright Treaty, que em seu art. 11 previa que cada estado "shall provide adequate legal protection and effective legal protection and effective legal remedies against the circumvention of effective technological measures that are used by authors in connection with the exercise of their rights under this Treaty or the Berne Convention and that restrict acts, in respect of their works, which are not authorized by the authors concerned or permitted by law"

Para Lessig, o grande problema deste sistema de regulação é que o uso não-autorizado de uma obra nem sempre é caracterizado como infração; os CMS desconsideram a importância que o uso livre tem para a sociedade. Nada assegura que os sistemas privados de proteção, como os trusted systems, irão incluir a previsão de uso livre conforme as previsões legais. O DMCA prevê algumas hipóteses de uso considerado livre, como a engenharia reversa, testes de segurança, pesquisa de criptografia e certos usos por bibliotecas. ${ }^{29}$

Como uma tecnologia de caráter transnacional poderia adequar-se às diversas particularidades que o uso livre teria de país para país? O problema é agravado ao observarmos que as decisões são tomadas em última instância pelos EUA, devido à força de suas empresas e leis. Exemplo foi o julgamento da empresa canadense ICraveTV. que transmitia programação televisiva pela Internet de forma permitida naquele país ${ }^{30}$, mas não nos EUA. Duas ações foram movidas contra aquela empresa, uma composta pela National Football League e National Basketball Association e outra composta por diversas empresas da indústria cinematográfica. De acordo com a medida cautelar concedida em favor das empresas americanas, a empresa canadense não deveria

\section{17 U.S.C. $\S \S 1201$ (d), (f), (g), (j)}

30. A argumentação de William Craig, fundador da cmpresa, cra de que suas atividades cstavam sujeitas ao Canadian Radio-Television and Tclecommunications Commission, que cximia as opcraçõcs de Internet de serem reguladas. A decisão sobre se suas atividades realmente infringiam ou não as Icis canadenses não chegou a ser resolvida, pois $\mathrm{cm}$ ocasião na qual cmpresas canadenses processavam a ICraveTV, um acordo foi firmado entre as partes. Para o professor da University of Ottawa, Michacl Geist, a ICraveTV não teria infringido qualquer lei canadense caso cstivesse apenas retransmitindo sinais inalterados. O ponto da discussão quc nos intercssa é que sc tais atividades fosscm consideradas legais $\mathrm{cm}$ território canadensc, não scriam pelas lcis americanas, que prcvalcccram após a decisão do juiz Donald Ziegler $\mathrm{cm}$ conceder medida cautelar contra as operações da empresa que tivessem cfeitos $\mathrm{cm}$ território americano. 
transmitir seu conteúdo para os EUA por noventa dias, o que implicou na suspensão completa de suas atividades. Três semanas depois da decisão americana, a ICraveTV e os querelantes entraram em acordo. Este é um exemplo de como casos onde deveria prevalecer a lex fori acabam tornando-se confusos em questões envolvendo a Internet.

Além do desafio imposto às hipóteses de uso livre, os CMS ameaçam a privacidade dos indivíduos na medida em que precisam de certos dados para sua correta operação. Pela descrição de Stefik, elementos como a idade do usuário e a sua vontade em fazer cópias da obra são informados ao sistema de gerenciamento das informações. Este sistema potencialmente teria muitas informações pessoais sobre seus usuários e sobre as obras consultadas por estes.

Para Julie Cohen, da Universidade de Pittsburgh, deveria existir uma forma legal de proteção à antiga anonímia existente antes do surgimento desta forma de monitorização. Existe um valor de "liberdade intelectual" de que possamos ler anonimamente. A respeito da ameaça ao uso livre, ela defende um direito de resistir, de burlar os trusted systems quando o uso for previsto pela lei como livre.

Estas soluções buscam realizar uma espécie de releitura. Porém não caracterizam a releitura completamente pois estamos tratando de questões inéditas, não previstas pelos legisladores devido às antigas relações de poder que impediam este controle de direitos autorais ${ }^{31}$

É justificado o medo de que a tecnologia possa prejudicar os autores, pela cópia e distribuição de material com facilidade, baixo custo e alta qualidade, em geral com impunidade. Entretanto as tendências de proteção da informação dos governos e indivíduos estão caminhando de forma abusiva; as técnicas contratuais ${ }^{32}$ e os CMS cada vez mais diminuem os direitos dos usuários, implantando um sistema de uso mediante pagamento; o uso livre fica ameaçado. Este exagero no exercício do controle é uma modalidade de oversteer, derrapagem. Shapiro é da mesma opinião de Cohen sobre a existência de um direito a burlar dos mecanismos de proteção:

"Government should recognize the importance of this breathing room, by adopting a rule analogous to fair use that might be known as 'fair hacking' or 'fair breach This would give individuals the right in certain limited situations to circumvent

31. O congresso amcricano debatcu muito cstas questões antes da aprovação da versão final do DMCA, conforme declaração do juiz Kaplan.

32. O problema cncontrado no sistema anglo-saxão imposto pclas cláusulas de ccssão de dircitos atravćs de clickthrough agreements c shrinkwrap licences ć amenizado no sistema jurídico pátrio, que considera muitas destas provisõcs abusivas c nulas de pleno dircito. 
technological protections of information or to ignore the provisions in clickwrap contracts. If legislatures fail to enact such exceptions, courts should find that constitutional principles, including the First Amendment, require that they be recognized."

\subsection{O caso DeCSS}

O juiz Lewis Kaplan trouxe uma resposta a este dilema nas últimas palavras de uma sentença de 89 páginas a respeito do caso DeCSS, no qual oito grandes estúdios cinematográficos americanos processavam os responsáveis pelo web site 2600.com, distribuidor do software DeCSS que permitia a fraude de mecanismos de proteção de DVDs.

O Content Scramble System (CSS) é um meio de controle de acesso e prevenção de cópia, desenvolvido pela indústria cinematográfica, com o uso de criptografia implementada de forma que apenas os aparelhos de reprodução de DVDs possam decifrar e reproduzir, mas não copiar, os filmes em DVDs. A tecnologia necessária para isto deve ser obtida através de licenciamento. O DeCSS é um software que permite a fraude ao sistema CSS dando o poder aos seus usuários a assistir a DVDs em aparelhos não-licenciados e inclusive fazer cópias digitais. Este software foi desenvolvido através de engenharia reversa por Jon Johansen, um norueguês de quinze anos de idade, junto com dois outros indivíduos que não tardaram em divulgá-lo na Internet em seus web sites pessoais.

Após essa divulgação inicial, vários web sites copiaram o software, que passou a ser disponivel em diversas fontes pela Internet. Cientes disto, os estúdios cinematográficos passaram a enviar diversas notificações extrajudiciais exigindo que o DeCSS não permanecesse disponível ao público, o que foi cumprido por parte considerável dos operadores daqueles web sites, mas não pelos réus. Em janeiro de 2000, Eric Corley foi processado por oferecer o DeCSS para download pelo web site de sua empresa, 2600 Enterprises, Inc.

Obedecendo à decisão da medida cautelar, o réu removeu o DeCSS do web site 2600.com, porém, no que chamaram de "electronic civil disobedience" instigaram diversos outros web sites a oferecer o software para download com um pedido que dizia "We have to face the possibility that we could be forced into submission. For that reason it's especially important that as many of you as possible, all throughout the world, take a stand and mirror these files" assim, buscando frustrar os fins dos autores e da decisão judicial de impedir a propagação do software. 
A argumentação do réu era de que o DMCA não deveria afetar sua conduta, pois se houver restrição de uso de mecanismos de fraude a sistemas de proteção à propriedade intelectual, isto prejudicaria aqueles que desejam obter acesso às obras protegidas com a intenção de exercer o uso livre (fair use). Assim, aqueles que desejam exercer o uso livre, não infrator, das obras protegidas precisam de meios como o DeCSS para burlar os meios de controle de acesso.

Os autores por sua vez empreenderam legitimamente capital e esforços para a produção de seus filmes na expectativa de obtenção de retorno econômico dentro da proteção concedida pelos institutos de propriedade intelectual. Para eles, o advento de novas tecnologias ñão deve abalar esta estrutura, de longa data.

De fato, os CMS têm a capacidade de prevenir tanto o uso infrator como o uso livre, surgindo um conflito entre o uso destas ferramentas de controle de acesso e o uso livre. Os réus, como observa Kaplan, não foram os primeiros a reconhecer esta possibilidade. O Congresso americano, no processo legislativo que deu origem ao DMCA, estava preocupado com esta questão. Os proponentes de medidas mais robustas de controle das obras intelectuais argumentavam que a proteção legal contra a fraude deveria ser essencial para que os titulares dos direitos intelectuais fossem devidamente protegidos. Seus oponentes respondiam dizendo que o monopólio inapropriado do copyright poderia prevenir o seu uso livre. Ao fim, o Congresso chegou a uma decisão, cujo mérito não deve ser discutido pelo Judiciário. A lei é clara em estabelecer que a publicação do DeCSS viola o DMCA.

Kaplan finaliza sua sentença apontando a impossibilidade do fair hack por' decisão judiciária, argumentando que "each side is entitled to its views. In our society, however, clashes of competing interests like this are resolved by Congress. For now, at least, Congress has resolved this clash in the DMCA and in plaintiffs favor. Given the peculiar characteristics of computer programs for circumventing encryption and other access control measures, the DMCA as applied to posting and linking here does not contravene the First Amendment. Accordingly, plaintiffs are entitled to appropriate injunctive and declaratory relief"

A decisão sobre a provisão da Section 1201 (a) (1) do DMCA que diz que "no person shall circumvent a technological measure that effectively controls access to a work protected under this title" só teria efeito após dois anos a partir de outubro de 1998 para que o Congresso tivesse tempo para investigar como melhor conçiliar os interesses privados e públicos, resultado que deve ser divulgado em breve. 


\section{Patentes de software}

As patentes são uma forma de regulação, um monopólio concedido pelo Governo. Este monopólio tem a finalidade de estimular a produção científica. Muitas pesquisas e invenções não teriam sido feitas sem a proteção governamental das patentes. Porém, a proteção demasiada não implica necessariamente em um aumento na produção científica, em especial para as questões do ciberespaço.

Os requisitos para a concessão de patentes como a novidade, não obviedade e utilidade são de difícil identificação em um novo campo, onde não existe um consenso sobre o atual estado da técnica, ou prior art. Assim, nos EUA, uma série de patentes duvidosas começou a ser aprovada pelo United States Patent and Trademark Office (USPTO) para criações relacionadas ao ciberespaço.

Uma decisão de segunda instância, reformando o entendimento anterior, abriu precedente para a aprovação das patentes de negócio (business methods patents) ${ }^{33}$ com o reconhecimento da patenteabilidade do sistema informatizado "hub and spoke" que manipulava os ativos de fundos de investimento dentro de um portfolio. A Corte reconheceu a sua utilidade prática, sendo suficiente a produção de um "useful, concrete and tangible result", mesmo se referido resultado fosse simplesmente expresso em números. Assim, o Federal Circuit deixou claro que a proteção às patentes não mais será negada com a justificativa de ter produção de resultados puramente numéricos ou serem simples métodos de negócios.

As críticas a este sistema argumentavam que a partir da implantação da comunicação pelo protocolo TCP/IP uma infinidade de novas possibilidades surgiu, não pelos frutos de esforços conduzidos por pesquisadores e capital investido, mas pelo fato de ser o TCP/IP uma linguagem versátil que permite muitas aplicações.

As business methods patents davam aos seus titulares um monopólio sobre a forma de condução de negócios que iniciassem por meios tecnológicos. Se isto já é preocupante no mundo material, no ciberespaço é mais ainda, pois não existe limite para este tipo de patente. A quase totalidade dos métodos de comércio eletrônico em princípio começam através de tecnologia, do Código. Assim, todos os métodos negociais de Internet são potencialmente patenteáveis.

O medo dos críticos a este sistema, que poderia ensejar a concessão de patentes a inúmeras aplicações, se concretizou: estranhos resultados têm sido aprovados

33. State Street Bank \& Trust Co. v. Signature Financial Group, Inc. Capturado cm 17 sct. 2000. Online. http://www.law.emory.edu/fedcircuit/july98/96-1327.wpd.htm! 
pelo USPTO. A patente americana número 5.715.314 por exemplo dá ao seu titular o monopólio a "network-based sales systems" o que é uma descrição demasiadamente genérica, podendo ser interpretada como qualquer atividade de comércio eletrônico. As críticas às patentes de negócio recrudesceram os critérios de análise do USPTO ${ }^{34}$, que incluirá uma ampla busca por documentos patentários americanos e literatura não-patentária, bem como um segundo nível de revisão para os pedidos aprovados.

Diante das patentes de software, cada vez mais as empresas de tecnologia têm se preocupado em estabelecer tanto estratégias defensivas, checando se suas atividades não infringem patentes existentes, como ofensivas ${ }^{35}$ garantindo que todas as suas idéias possam ser expressas sob a forma de patentes.

O Congresso americano tem forçado cada vez mais a produção de novas leis aumentando a proteção da propriedade intelectual de forma geral. A proteção concedida pelas patentes, como vimos, é uma forma de regulação pelo Governo que tem um forte fundamento econômico. No contexto da nova economia, questionamos os benefícios econômicos trazidos pelas patentes de software. Estaria o equilíbrio da propriedade intelectual resguardado neste contexto?

A Amazon.com, após receber sua patente número 5.960.411 para a tecnologia one-click purchasing 36 sobre "method and system for placing a purchase order via a communications network" causou grande furor, principalmente para Richard Stallman, fundador da Free Software Movement, que argumentou que um boicote deveria ser feito àquela empresa ${ }^{37}$, quando esta usou sua patente sobre esta óbvia e importante tecnologia ${ }^{38}$ contra a sua concorrente, BarnesandNoble.com, obtendo liminar em $1^{\circ}$ de dezembro de 1999, manifestando sua intenção de monopolizar o comércio eletrônico.

34. USPTO. Business Methods Patent Initiative: An Action Plan. Capturado cm 17 set. 2000. Onlinc http://www.uspto.gov/wcb/offices/com/sol/actionplan.html

35. É a recomendação de diversos consultores americanos, como David Kline, no artigo "The Best Offensc Is a Pit Bull Patent Lawycr", publicado na Revista e Company Now, de junlı de 2000.

36. USPTO. Method and system for placing a purchase order via a comminications network. Capturado cm 17 sct. 2000. Onlinc. http://www.gnu.org/philosophy/amazonpatent.html

37. Richard Stallman, Boycott Amazon!. Capturado cm 17 sct. 2000. Onlinc. http://www.gnu.org/ philosophy/amazon.htm!\#whyBoycott

38. Atravćs de um pequeno arquivo, o cookie, o browser pode manipular informaçõcs sobre a identidade do consumidor no processo de compra 
Em resposta às inúmeras críticas que recebeu da comunidade online, Jeff Bezos, presidente da Amazon.com, divulgou uma carta aberta, em que reconhece que as patentes prejudicam o desenvolvimento do comércio eletrônico e propõe algumas mudanças, como a diminuição do prazo de proteção ${ }^{39}$ Entretanto, Bezos afirmou que não pretende abdicar as suas patentes voluntariamente. Em fevereiro, a Amazon.com anunciou que recebeu uma patente para o software relacionado ao seu programa de filiação que pode causar comoção maior do que a patente one-click. O programa de filiação permite que outros web sites façam um link para a Amazon.com e recebam uma comissão pelas vendas efetuadas pelas suas "indicações" Várias outras empresas usam um sistema similar.

Se não respeitarmos o equilíbrio que este instituto deve ter, os custos serão maiores que os benefícios. A objeção deste monopólio pelos seus teóricos beneficiários, algumas empresas de software, incluindo grandes nomes como Oracle e Adobe, indica que talvez não seja esta a melhor alternativa para lidar com a questão, pois o processo de desenvolvimento de software pode tornar-se muito caro.

Este problema é muito perigoso, principalmente no contexto do comércio internacional. Para usar uma idéia oul tecnologia no ciberespaço, as pessoas deveriam entrar em contato com companhias americanas, detentores de praticamente todas as patentes relacionadas a tecnologias para Internet. Este mercado global tendencioso deve ser combatido.

Luiz Olavo Baptista informa que, já em 1979, Alan Salzman previa os efeitos dos conflitos de tratamento internacional à proteção do software e o poder econômico americano, afirmando que "o grossso da sua produção ocorrem neste país. Mas, assim como é impossivel avaliar os efeitos domésticos potenciais da patenteabilidade dos programas, não é possivel avaliar os efeitos que uma decisão unilateral dos Estados. Unidos teriam para encorajar desenvolvimentos similares em outros paises"

Observamos hoje esses efeitos: após diversas formas de pressão, o Japão incorporou ao seu sistema jurídico a previsão de proteção a patentes de software. A questão, levada ao conselho administrativo do European Patents Office, tende à aprovação de patentes de software támbém para a Europa, como já manifestado em controversa votação $0^{40} \mathrm{de} \mathrm{dez}$ votos a favor e nove contra. Ainda em novembro deste

39. Jeff Bezos, An open letter from Jeff Bezos on the subject of patents. Capturado $\mathrm{cm} 17 \mathrm{set} .2000$. Online. http://www.amazon.com/exec/obidos/subst/misc/patents.litml/102-3131897-1582554

40. Verlag Hcinz Hcisc, Europäisches Patentamt befiiwortet Software-Patente. Capturado cm 17 sct. 2000. Onlinc. http://www.heisc.de/ncwsticker/data/odi-14.09.00-000/ 
ano uma conferência será feita para ratificar esta decisão. Isto insinua uma tendência de exportação das leis americanas para o mundo. Se aprovada, o software na Europa receberá tanto o tratamento autoral como patentário.

Seria necessária a proteção por patentes para o software uma condição de desenvolvimento desta indústria? A resposta não é simples. $O$ aumento de patentes aumenta os incentivos e os custos. De acordo com estudo feito pelo Massachusetts Institute of Technology, ${ }^{41}$ estas patentes já prejudicaram o investimento em pesquisa e desenvolvimento de software nos Estados Unidos.

Com o aumento de patentes nas mais básicas funções de desenvolvimento de software, aumentam as possibilidades de "infrações" comprometendo o processo de desenvolvimento do software. Richard Stallman assim descreve o ambiente atual nos Estados Unidos: "Imagine that each time you made a software design decision, and especially whenever you used an algorithm that you read in a journal or implemented a feature that users ask for, you took a risk of being sued."

Para a advogada nova iorquina Marylee Jenkins o comissário Todd Dickinson tem autoridade para realizar o reexame das patentes, o que já aconteceu no caso de uma retomada de patente concedido a um inventor da Califórnia sobre sistema para a correção do bug do milênio. ${ }^{42}$ "I could see the commissioner using his discretionary power here if there's a loud outcry from a segment of the industry", diz Jenkins.

Em resposta a uma crítica de que muitas patentes óbvias têm sido concedidas pelo USPTO, Dickinson respondeu que "the courts have told us that computer software is patentable. People like to be able to protect their creativity and investments. The goal is to make sure this doesn 't unnecessarily impede technological advancement" O seu conselho foi que se o USPTO conceder patentes e os interessados puderem demonstrar que o exame falhou na consideração do atual estado da técnica, que o façam ${ }^{43}$

\section{Conclusão}

Não se pode ignorar o impacto que a revolução digital trouxe a todos os aspectos de nossa sociedade, elevando o patamar de relacionamento humano com a implantação de técnicas moleculares.

41. Disponivel $\mathrm{cm}$ http://www.rescarchoninnovation.org/patent.pdf

42. USPTO, Patent and Trademark Office Orders Recxamination of Y2K Fix Patent. Capturado $\mathrm{cm} 17$ set. 2000. Onlinc. http://www.uspto.gov/web/offices/com/spceches/99-51.htm

43. USPTO, Transcript of PTO commissioner's on-line discussion. Capturado $\mathrm{cm} 17 \mathrm{set}$. 2000. Onlinc. http://www.uspto.gov/wçb/officcs/com/chats/chat0002.htm 
Diante deste processo de evolução, o Governo deve tomar uma posição, intervindo, quando necessário, de forma equilibrada. Cabe ao poder legislativo a decisão de quais leis devem ser implantadas e como.

Observamos que em alguns momentos a intervenção governamental é necessária, pois os indivíduos não podem se auto-regular sozinhos, como no caso dos Copyright Management Systems. A ausência de previsões antifraude por leis como a DMCA anularia os efeitos de proteção que o setor privado produz. Em dezembro de 1996, a Organização Mundial da Propriedade Intelectual produziu o "WIPO Copyright Treaty", que em seu art. 11 prevê que os Estados deverão prever meios legais adequados e sanções contra a fraude de meios tecnológicos usados pelos autores na proteção de seus direitos. Casos como este, que requerem trabalho legislativo, devem fazer una delicada análise dos princípios existentes nas leis anteriores, dos valores que estas desejam proteger. Assim, a "derrapagem" dos indivíduos é controlada.

Em outras áreas, entretanto, a regulação pode ser prejudicial, e a "derrapagem" pode acontecer não pela tentativa de controle individual, mas governamental, como no caso da proteção patentária para o software, prejudicando um setor que tem condições de progredir independentemente do monopólio concedido pelo Governo.

A revolução digital amplia a nossa liberdade, podendo causar conflitos de interesses. A resposta a estes conflitos deve ser dada pela imposição de limites às nossas liberdades: Dalmo de Abreu Dallari, opondo-se à doutrina individualista da liberdade, alertava que o homem, como ser social, deve ter sua liberdade concebida tendo em vista o homem social, o homem situado, que não-existe isolado da sociedade. A liberdade humana é, assim, uma liberdade social, que leva em conta o relacionamento de cada indivíduo com todos os demais, o que implica em deveres e responsabilidades. $\mathrm{O}$ espírito da liberdade é aquele que pesa os interesses pessoais com os coletivos.

Os governos, corporações e poderes institucionais devem reconhecer a liberdade individual, trazida pelas inovações tecnológicas, que possibilitam a tomada de decisões inéditas. Os indivíduos, por sua vez, devem aceitar o desafio de ser cada vez mais responsáveis, pelo seu próprio bem-estar e o da sociedade coletiva. Devem, assim, reconhecer certos limites. Esta é a noção de equilíbrio.

Aí encontra-se o papel do Direito, nas sábias palavras do professor Miguel Reale: "O ideal é que cada homem possa realizar os seus fins da maneira mais ampla, mas é intuitivo que não poderia coexistir o arbitrio de cada um com o dos demais sem 
uma delimitação harmônica das liberdades, consoante clássico ensinamento de Kant. Desse modo, o Direito delimita para libertar: quando limita, liberta. ${ }^{\prime 44}$

São Paulo, setembro de 2000.

44. Realc, 1974 , p. 72 
Bibliografia

ASCENSÃO, José de Oliveira. Direito Autoral. $2^{\mathrm{a}}$ ed. Rio de Janeiro: Renovar, 1997.

BAPTISTA, Luiz Olavo. Aspectos Juridicos das Transferências Eletrônicas Internacionais de Fundos. São Paulo, 1986. Tese (Livre Docência em Direito Internacional Privado) - Faculdade de Direito, USP, 1986.

. A Vida dos Contratos Internacionais. São Paulo, 1993. Tese (Titular de Direito Internacional Privado) - Faculdade de Direito, USP, 1993.

A proteção dos programas de computador em direito comparado $e$ internacional, Revista Forense, v. 293, pp. 121-130. Conferência proferida no "Seminário sobre Aspectos Jurídicos do Software", organizado pela SEI; 6 de out. 1981, Brasília.

BASSO, Maristela. Contratos Internacionais do Comércio. $2^{\mathrm{a}}$ ed. Porto Alegre: Livraria do Advogado, 1998.

. O Direito Internacional da Propriedade Intelectual. 1.ed. Porto Alegre: Livraria do Advogado, 2000.

BITTAR, Carlos Alberto. Direito de Autor. Rio de Janeiro: Forense, 1997.

BOBBIO, Norberto. Teoria dell 'ordinamento giuridico. Torino: Giappichelli, 1970.

CASTELLS, Manuel. A Sociedade em Rede. $3^{a}$ ed. São Paulo: Paz e Terra, 1999. $617 \mathrm{p}$.

DALLARI, Dalmo de Abreu. Elementos de Teoria Geral do Estado. 19" ed. São Paulo: Saraiva, 1995.

DOHANEY, M. Scott. Dispute Resolution in Cyberspace. Journal of International Arbitration. Great Britain, 15(4): 127-168, 1998.

FOUCAULT, Michel. Microfisica do Poder. 14a ed. Rio de Janeiro: Graal, 1999

GRECO, Marco Aurélio. Internet e Direito. 1.ed. São Paulo: Dialética, 2000.

HUET, Pierre (Org.). Le droit du multimédia - de la télématique à Internet. Paris: Editions du téléphone, 1994.

JESSUP, Philip C. Direito Transnacional. $1^{\text {it }}$ ed. São Paulo: Editora Fundo de Cultura, $1965.92 \mathrm{p}$.

JORDAN, Tim. Cyberpower: The Culture and Politics of Cyberspace and the Internet. $1^{\text {st }}$ ed. London: Routledge, 1999.

KATSH, Ethan. Law in a Digital World. New York: Oxford University Press, 1995.

LESSIG, Lawrence. Code and Other Laws of Cyberspace. $1^{\text {st }}$. ed. New York: Basic Books, 1999. 
LÉVY, Pierre. A Inteligência Coletiva: por um antropologia do ciberespaço. $2^{\mathrm{a}}$ ed. São Paulo: Edições Loyola, 1999. 212 p.

de LUCCA, Newton (Org.). Direito \& Internet: Aspectos Juridicos Relevantes.

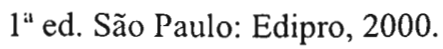

PEIRCE, Charles S. Semiótica. 2a ed. São Paulo: Perspectiva, 1995.

REALE, Miguel. Lições preliminares de Direito. 1" ed. São Paulo : José Bushatsky, 1974.

Linha evolutiva da teoria tridimensional do Direito. Revista da Faculdade de Direito. São Paulo, v. 88, pp. 301 - 312, 1993.

Teoria Tridimensional do Direito. $1^{\text {a }}$ ed. São Paulo: Saraiva, 1968.

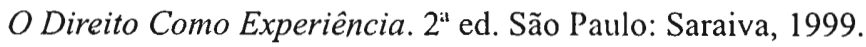

Fundamentos do Direito. $3^{\text {al }}$ ed. São Paulo: RT, 1998.

RHEINGOLD, Howard. A Comunidade Virtual. 1" ed. Lisboa: Gradiva, 1996.

SHAPIRO, Andrew. The Control Revolution: How the Internet is Putting Individuals in Charge and Changing the World We Know. $1^{\text {st }}$. ed. New York: Public Affairs, 1999. Online

BARLOW, John Perry. Selling wine without bottles: the economy of mind on the global net. Capturado em 17 set. 2000. Online. Disponivel na Internet: http://www.eff.org/pub/Publications/John_Perry_Barlow/HTML/ idea_economy_article.html

BOYLE, James. Foucault in Cyberspace: Surveillance, Sovereignty, and HardWired Censors. Capturado em 17 set. 2000. Online. Disponível na Internet: http://www.tprc.org/abstracts97/foucault.htm

CLARK, Charles. The copyright environment for the publisher in the digital world. Capturado em 17 set. 2000. Online. Disponivel na Internet:

http://associnst.ox.ac.uk/ icsuinfo/clark.htm

COHEN, Julie E. Copyright and the jurisprudence of self-help. Capturado em 17 set. 2000. Online. Disponível na Internet:

http://eon.law.harvard.edu/h2o/property/alternatives/self-help.html

Lochner in cyberspace: the new economy orthodoxy of "rights management". Capturado em 17 set. 2000. Online. Disponivel na Internet:

http://eon.law.harvard.edu/h2o/property/alternatives/cohen 1.html

Some reflections on copyright management systems and laws designed to protect them. Capturado em 17 set. 2000. Online. Disponivel na Internet: http://www.law.berkeley.edu/journals/btlj/articles/12_1/Cohen/html/text.html 
HAUBEN, Michael. The Expanding Commonwealth of Learning: Printing and the Net Capturado em 17 set. 2000. Online. Disponivel na Internet: http://wuarchive.wustl.edu/doc/misc/acn/netbook/ch.9_printing

INTERNET ENGINEERING TASK FORCE. Overview of the IETF. Capturado em 11 fev. 2000. Online. Disponível na Internet http://www.ietf.org/overview.html

INTERNET SOCIETY. All about the Internet: History. Reston, 2000. Capturado em 26 jan. 2000. Online. Disponível na Internet http://www.isoc.org/internet/history/ cerf.html

LESSIG, Lawrence. Cyberspace's Constitution. Capturado em 15 fev. 2000. Online. Disponivel na Internet: http://cyber.law.harvard.edu/works/lessig/AmAcd1.pdf . Governance. Capturado em 21 jan. 2000. Online. Disponível na Internet: http://cyber.law.harvard.edu/works/lessig/final.pdf

Reading the Constitution in Cyberspace. Capturado em 02 fev. 2000. Online. Disponivel na Internet: http://papers.ssrn.com/ paper.taf?ABSTRACT_ID=41681\#Paper\%20Download . Reclaiming a Commons. Capturado em 11 nov. 1999. Online. Disponível na Internet: http://cyber.law.harvard.edu/events/lessigkeynote.pdf The Law of the Horse: What Cyberlaw Might Teach. Capturado em 21 jan. 2000. Online. Disponivel na Internet: http://cyber.law.harvard.edu/works/lessig/ finalhls.pdf

National Telecommunications and Information Administration. DNS Statement of Policy. Washington, 1998. Capturado em 24 jan. 2000. Online. Disponível na Internet http://www.ntia.doc.gov/ntiahome/domainname/6_5_98dns.htm

RODITTI, Esther C. Is self-help a lawful contractual remedy? Capturado em 17 set. 2000. Online. Disponível na Internet:

http://eon.law.harvard.edu/h2o/property/alternatives/roditti.html

STEFIK, Mark. Trusted Systems. Capturado em 09 dez. 1999. Online. Disponivel na Internet: http://www.sciam.com/0397issue/0397stefik.html

Shifting the possible: how trusted systems and digital property rights challenge us to rethink digital publishing. Capturado em 17 set. 2000. Online. Disponível na Internet: http://www.law.berkeley.edu/journals/btlj/articles/12_1/Stefik/html/ text.html. 